\title{
The Acceptability of Faecal Microbiota Transplant for Anterior Resection Syndrome (AFFINITY) Study
}

\author{
Anna Powell-Chandler ${ }^{1, *(\mathbb{D}}$, Kathleen L. Withers ${ }^{2} \mathbb{D}$, Grace Carolan-Rees ${ }^{2}$ and Julie A. Cornish ${ }^{3}$ \\ 1 Health Education and Improvement Wales, Nantgarw CF15 7QQ, UK \\ 2 Cedar Healthcare Technology Research Centre, Cardiff Medicentre, Heath Park, Cardiff CF14 4UJ, UK; \\ kathleen.withers@wales.nhs.uk (K.L.W.); Grace.Carolan-rees@wales.nhs.uk (G.C.-R.) \\ 3 Department of Colorectal Surgery, University Hopsital of Wales, Heath Park, Cardiff, CF14 4XW, UK; \\ Julie.Cornish@wales.nhs.uk \\ * Correspondence: annapc@doctors.org.uk
}

Received: 28 May 2020; Accepted: 18 June 2020; Published: 21 June 2020

\begin{abstract}
Low anterior resection syndrome (LARS) is recognised as disordered bowel function after rectal resection. Temporary ileostomy is associated with LARS and with reduced colonic bacteria. Faecal microbiota transplant (FMT) is the introduction of enteric bacteria from healthy donors into a patient's gut. We hypothesise that FMT could improve bowel function after ileostomy reversal. We aim to determine whether FMT would be acceptable to patients. Patients who had undergone anterior resection in the previous two years across four sites were sent questionnaires. A group of patients were invited to a focus group to explore their views further. There were 98 eligible patients, of whom 40 responded (41\%); 67\% were male, median age was 67 (range 31-83) years, and 11 still had a stoma. Of those who had their stoma reversed, $52 \%$ had major LARS symptoms. Sixty-five percent thought the concept of FMT sounded effective and 70\% were willing to try it. A healthy anonymous donor and FMT via enema were the most acceptable options to the respondents. Seven patients attended the focus group; 2 female, 5 male, mean age 66 (range 45-75) years. All patients thought FMT was acceptable but the word "faecal" made it less acceptable. All participants would consider entering a trial with FMT as a treatment option. The main concerns were safety and efficacy. The majority of patients who responded thought FMT was acceptable and were willing to try it as a potential treatment option.
\end{abstract}

Keywords: faecal microbiota transplant; anterior resection; ileostomy; LARS

\section{Introduction}

Colorectal cancer is the fourth most common cancer in the UK with over 42,000 new diagnoses per year. The five-year survival rate is currently around $60 \%$ [1]. Surgical resection with curative intent is the primary treatment for most patients. Whilst more patients are avoiding a permanent stoma by having an anterior resection for rectal tumours, there is a trade-off for patients in terms of their quality of life due to impaired bowel function [2].

The use of a temporary ileostomy to cover a pelvic anastomosis following anterior resection for a mid to low anastomosis is now considered standard practice for most colorectal surgeons in the UK following the publication of the 2007 ACPGBI Management of Colorectal Cancer Guidelines [3]. The use of a temporary ileostomy reduces the mortality associated with an anastomotic leak [4] but although these stomas are intended to be temporary, recent national bowel cancer audit data reports that only $65 \%$ are reversed within 18 months [5]. 
Increasing awareness amongst clinicians of the cluster of bowel symptoms that can follow after rectal cancer surgery and the development of the LARS score from the group in Arhus, Denmark [6], has led to the use of the term LARS (Low Anterior Resection Syndrome).

The aetiology of LARS is thought to be multifactorial, with the potential of sphincter injury during the construction of the anastomosis, alterations in anorectal physiology and the development of a pudendal neuropathy [7]. The presence of a temporary ileostomy is associated with anterior resection syndrome [8,9]. This may reflect a lower anastomosis, use of neoadjuvant radiotherapy and prolonged inactivity of the pelvic floor. However, a study by Son et al. (2013) suggested that bowel dysfunction after stoma reversal may be related to diversion colitis. This study of 30 patients undergoing low anterior resection and temporary ileostomy creation found that all patients had inflammation (endoscopically and histologically) prior to stoma reversal with $57 \%$ having inflammation after reversal. Thirty percent of these patients had symptoms of diarrhoea after reversal and this was significantly associated with severity of diversion colitis [10]. Another study which compared patients with and without a stoma after surgery for rectal cancer demonstrated a significant reduction in colonic bacteria in those with an ileostomy. They also found that the severity of diversion colitis was associated with the presence of Bifidobacterium [11].

Faecal microbiota transplantation (FMT) is the introduction of beneficial bacteria from the faeces of healthy donors into the gut of patients with reduced diversity of intestinal bacteria. FMT is a recognised and National Institute for Health and Care Excellence (NICE) approved treatment for Clostridium difficile infection [12] and has also been shown to induce clinical remission in patients with ulcerative colitis (UC). Paramsothy et al. (2017) randomised 85 patients with active UC to receive either FMT or placebo. Steroid-free remission was achieved in $27 \%$ of those who received FMT and $8 \%$ placebo $(p=0.021)$ [13]. There have been few studies that have looked at the role of FMT in functional bowel disorders but there is some evidence that it may improve symptoms, again by correcting the balance of enteric bacteria [14].

We hypothesise that FMT could improve bowel function in patients after ileostomy reversal. Before any interventional trial can be considered, it is important to assess the acceptability of the intervention to patients. Previous studies that examined the acceptability of FMT for Clostridium difficile infection and UC suggested that factors such as level of education and severity of disease might influence acceptance. A recent study found that acceptability could be improved with provision of information about FMT to help improve understanding of what it involves and the reasons for carrying it out [15].

In order to explore acceptability of FMT in patients prior to ileostomy reversal, we developed a research study to gain a better understanding of patients' concept of FMT and determine whether we can provide information to improve acceptability and increase recruitment to future trials.

\section{Materials and Methods}

Ethics approval was granted by London Bridge Research Ethics Committee (reference 18/LO/0771). The study was comprised of 2 components; a postal survey asking patients about the acceptability of FMT and a focus group exploring the factors that predict acceptability. To be eligible for inclusion in this study, patients were required to be aged 18 years or over, able to provide informed consent in English or Welsh and to have undergone anterior resection with a defunctioning ileostomy in the previous 2 years. Patients who had a palliative diagnosis at the time of surgery or since surgery were excluded. Potential participants from four Health Boards (Cardiff and Vale UHB, Cwm Taf Morgannwg UHB, Aneurin Bevan UHB and Swansea Bay UHB) were identified through the Cancer Network Information System Cymru (a prospectively maintained register of all patients diagnosed with cancer in Wales).

Identified, eligible patients were sent a pack containing a letter of invitation, a participant information sheet (PIS), and a consent form together with a specially designed questionnaire and a prepaid envelope. Non-responders were sent a reminder letter with a replacement pack 
approximately 6 weeks after the initial mailing. The survey included questions on patient demographics, surgical history, current symptoms (LARS score), prior knowledge of FMT and acceptability of FMT (Appendix A). Patients were also asked on the consent form to indicate if they would be willing to be contacted in relation to taking part in a focus group. A group of these patients were contacted by a researcher independent to the clinical group and invited to a focus group in which their views on FMT were explored further to aid the design of educational material.

The focus group took place in June 2019. An exploratory topic guide was used with questions falling under three main themes to prompt initial discussions, with additional questions to be added as required during discussions (Appendix B). Data were analysed thematically using an inductive exploratory approach.

\section{Results}

\subsection{Survey Results}

Questionnaires were sent to 98 patients across the four sites, and 40 completed surveys were received, giving a completion rate of $41 \%$. Of those that responded, $67 \%$ were male and of those that did not respond, $69 \%$ were male. Both respondents and non-respondents had a median age of 67 years. Table 1 shows the demographics of respondents. Eleven patients were still awaiting ileostomy reversal. For the 29 patients who had had their stoma reversed, 7 (24\%) had minor LARS and $15(52 \%)$ had major LARS symptoms (Table 2). Details of the score can be found in the questionnaire in Appendix A.

Table 1. Demographics of respondents.

\begin{tabular}{|c|c|c|}
\hline Demographic & & $\begin{array}{l}\text { Responses } \\
\mathrm{n}=40(\%)\end{array}$ \\
\hline \multirow{2}{*}{ Ethnicity } & White British & $38(95)$ \\
\hline & Did not answer & $2(5)$ \\
\hline \multirow{6}{*}{ Marital Status } & Married/Civil Partnership & $24(60)$ \\
\hline & Separated/Divorced & $6(15)$ \\
\hline & Cohabiting & $3(7.5)$ \\
\hline & Single & $3(7.5)$ \\
\hline & Widowed & $3(7.5)$ \\
\hline & Did not answer & $1(2.5)$ \\
\hline \multirow{6}{*}{ Level of education } & Degree & $8(20)$ \\
\hline & A Level & $5(12.5)$ \\
\hline & GCSE & $14(35)$ \\
\hline & No qualification & $6(15)$ \\
\hline & Other & $6(15)$ \\
\hline & Did not answer & $1(2.5)$ \\
\hline \multirow{6}{*}{ Employment } & Employed full time & $4(10)$ \\
\hline & Employed part time & $6(15)$ \\
\hline & Full time education & $1(2.5)$ \\
\hline & Retired & $18(45)$ \\
\hline & Self-employed & $10(25)$ \\
\hline & Unemployed & $1(2.5)$ \\
\hline
\end{tabular}

Table 2. Low anterior resection syndrome (LARS) score of respondents.

\begin{tabular}{cc}
\hline LARS Score & Responses $\mathbf{n}=\mathbf{2 9} \mathbf{( \% )}$ \\
\hline $0-20$ (No LARS) & $7(24)$ \\
\hline 21-29 (Minor LARS) & $7(24)$ \\
\hline 30-42 (Major LARS) & $15(52)$ \\
\hline
\end{tabular}


The majority of participants ( $85 \%$ ) had not previously heard of FMT. After reading the information provided, the majority of participants responded that they "very much", "quite a bit" or "somewhat" thought that FMT was appropriate, would fit their lifestyle, seemed effective and would be willing to try FMT. Figure 1 shows the responses to the individual questions. The most popular donor type was an anonymous donor and the most popular delivery route was via enema.

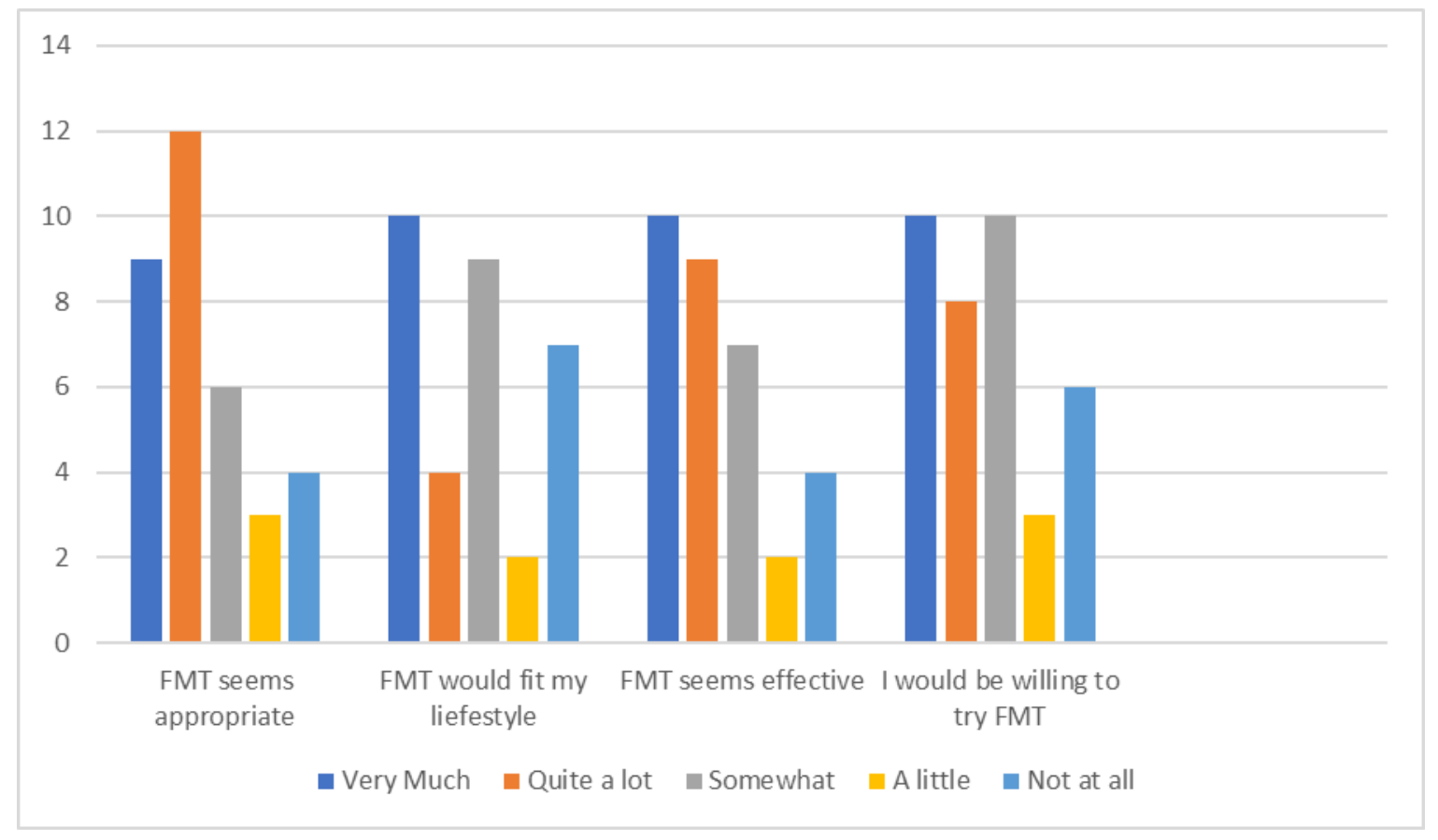

Figure 1. Participant responses.

Table 3 shows the demographics of those who were "very much" or "quite a bit" willing to try FMT compared with those who were "a little" or "not at all". Those who were willing to try FMT were slightly younger ( 69 vs. 73 years), more likely to be in work or education ( $56 \%$ vs. $33 \%$ ), more likely to still have their stoma ( $40 \%$ vs. $0 \%)$ and were more likely to have previously heard of FMT ( $27 \%$ vs. $11 \%$ ) and were less likely to have major LARS symptoms (33\% vs. $44 \%$ ).

Table 3. Comparison of participants willing to try FMT and not willing to try FMT.

\begin{tabular}{ccc}
\hline Demographics & $\begin{array}{c}\text { Willing to Try FMT } \\
\text { Very Much/Quite a Bit } \\
\mathbf{n = 1 8} \mathbf{1 \%})\end{array}$ & $\begin{array}{c}\text { Not Willing to Try FMT } \\
\text { A Little/not at all } \\
\mathbf{n = 9} \mathbf{9})\end{array}$ \\
\hline Male & $10(56)$ & $5(56)$ \\
Median age (range) & $69(31-79)$ & $73(38-80)$ \\
Degree level education & $5(28)$ & $1(11)$ \\
No qualification & $3(17)$ & $1(11)$ \\
In work/education & $10(56)$ & $3(33)$ \\
Married/cohabiting & $11(61)$ & $7(78)$ \\
Previously heard of FMT & $5(28)$ & $1(11)$ \\
Have stoma & $8(44)$ & $0(0)$ \\
Major LARS & $6(33)$ & $4(44)$ \\
\hline
\end{tabular}




\subsection{Focus Group Results}

Twelve patients from Cardiff \& Vale UHB agreed to being contacted in relation to participating in a focus group on the acceptability of FMT in patients undergoing ileostomy reversal. One was unreachable, two decided they did not want to take part (one of which felt FMT was "too disgusting" to talk about) and two were unable to make the arranged date, leaving seven patients that attended the focus group.

Of the attendees, two were female and five male and the ages ranged from 45 to 75 with a mean age of 66 years. Four currently had an ileostomy while the remaining three had previously had an ileostomy which had been reversed at the time of the focus group. Four members of the group knew nothing about FMT other than what they had read in the postal survey and been told in the introduction. However, one had heard "something about it on the radio" and then read up on the subject a little bit, and another participant had read up on it since being invited to the focus group. Another participant worked in health care and knew about the use of FMT for Clostridium difficile infection.

When discussing the acceptability of FMT, the participants in the focus group all thought that it was acceptable to them in theory and said they would at least consider it if it were thought to be potentially beneficial to them. Three expressed similar opinions of being "willing to try anything that helped", with one stating: "I would definitely consider it .... I had my stoma reversed 12 months ago and it's only now that I'm getting better. I've found life really difficult." Everyone in the group was very open to the idea of discussing FMT with their close family, and some participants also suggested they would be happy to discuss it with friends and colleagues.

Those present felt strongly that the word "faecal" was less than ideal in the description of any medical treatment as it is seen as unacceptable within society. One participant suggested that simply dropping the word "faecal" and calling it "microbe transplant" would improve its acceptability. One participant thought it was very important to make it clear that the transplant liquid is clear "to take the visual link of faeces away" and also thought it should be referred to in the same way as probiotic yogurts.

Five of the six participants thought that administration via a stoma would be acceptable for them, "through the stoma would be fine. You are used to it being used for different things due to blockages etc.", although one thought that it would be important to clarify exactly how this would be administered.

The group discussed their preferences for who they thought would be acceptable to use as a donor. One responder had no preference, one said they would prefer their spouse to be a donor if they had a choice and three others agreed that a stranger would be most acceptable, "you don't know who it is (from) when you have a blood donation, I think it should be the same". No one thought that anyone other than a stranger or spouse was acceptable.

On discussing patient information, there was a consensus that the participants were "not interested in receiving glossy leaflets anymore" and that short, concise information was preferred with signposts to additional information if it was required. The group all agreed that the information they usually receive is too positive and feels unrealistic. There was a request for balanced information with most of the participants suggesting that it would be useful to focus on the positives but also to have some negative information in the literature they receive. Patient stories were thought to be useful.

In considering participation in a trial, the inclusion of safety and efficacy of the treatment was paramount to all participants. When the discussions clarified that efficacy data is not yet available, the participants suggested that the theory behind the potential usefulness of FMT for anterior resection syndrome, how it might work, and its success and complication rates for other conditions would be useful in helping them make any decision in receiving FMT. Discussions around what would make participating more or less acceptable focused on the length of any treatment regime, with all participants being more likely to take part in a study which did not require an overnight stay. Three were more likely to take part if a treatment was a one-off and not a series of treatments over a period of time. 


\section{Discussion}

The majority of patients who responded to the questionnaire and attended the focus group found FMT to be acceptable and were willing to try it. However, there are limitations as to the conclusions that can be drawn from these results.

Survey respondents and focus group participants are self-selected and so results from these studies are likely to result in a degree of bias. Even with purposive sampling, focus groups require attendees to be confident in discussing the subject matter with a group of (usually) strangers. For subjects such as the one under discussion involving faecal transplants and bowel surgery, many patients may be disinclined to take part, as illustrated by the patient who declined to participate in the focus group because FMT was "too disgusting" to talk about in public. This bias means that it is challenging to get fully representative feedback. It is also possible that focus group attendees may be those people who have a particular interest in research, benefitting others or getting involved with less mainstream methods of healthcare. However, even with this bias, surveys and focus groups are a useful method of gaining honest feedback from a range of people within any targeting subgroup [16]. When considering new and experimental treatments, which also have a tendency towards biased recruitment, feedback from individuals who are inclined to participate in innovative work is arguably preferred.

The number of attendees in the focus group was small but was in keeping with accepted numbers for a focus group, which suggest five to be the minimum number of participants [17]. As only one focus group was carried out, it is possible that not all viewpoints will have been explored. However, as this is such a new area of research, even relatively limited feedback from informed and knowledgeable patients is highly valuable and the insight we have received will provide useful in meeting our aims.

Since this study took place, there has been controversy around trials involving FMT which the participants in the study would not have been aware of at the time. There has been a report of two patients in the USA that became unwell during a clinical trial of FMT and one patient subsequently died. They had received FMT from the same donor. Following this in June 2019, the Food and Drug Administration (FDA) suspended clinical trials using FMT in the USA [18]. An official statement from the UK Gut Microbiota for Health Expert Panel in relation to this reported that the donors and FMT samples in the trial in the USA were not screened for Extended Spectrum Beta Lactamase (ESBL)-producing bacteria, which is suggested by UK British Society of Gastroenterology and Healthcare Infection Society Guidelines [19]. Trials involving FMT in the UK have not been suspended.

Our focus group feedback suggests that recruitment onto an RCT in this patient group is feasible, and their thoughts on what information should be included in patient information sheets, and indeed how these should look provides a valuable starting point for developing a future patient-facing study and treatment materials. Future patients who might be considering FMT for LARS will have been through a significant treatment journey to become experts in this field. Their prior experiences mean that they have already had extensive contact with the NHS and judging from the feedback we have received, may be selective in the information they want to receive. The use of focused, concise and realistic information is essential in supporting them make important decisions with additional provision such as support groups, and internet sites where available.

The participants had not heard about the suspension of trials involving FMT in the USA at the time of the focus group and this may have affected their responses and views on FMT. One participant did reference the historic blood transfusion safety scandal, highlighting the need for any clinical trial involving FMT to adhere to the highest possible safety standards and also the need for transparency with patients over the potential risks. Clearly, any future studies would need to consider the safety of a trial as well as participants' willingness. Although FMT is a recognised treatment in the UK, due to unidentified composition of faecal bacteria, its safety remains controversial [20]. Guidelines suggest particular caution in immunosuppressed patients [19] which, as patients who have undergone cancer surgery, our participants may be. The current COVID-19 pandemic also serves as a reminder of the risk of new transmissible diseases and may also influence future potential participants' readiness to partake in such trials. 


\section{Conclusions}

The findings suggest that while some patients find the idea of FMT for LARS unacceptable, for others, the potential benefit, even when hypothetical, would make this treatment option acceptable. The focus group feedback suggests that recruitment onto an RCT in this patient group is feasible, although this could be affected by the recent suspension of FMT trials in USA.

Author Contributions: Conceptualization, J.A.C. and A.P.-C.; methodology, J.A.C., A.P.-C., K.L.W. and G.C.-R.; formal analysis, J.A.C., A.P.-C., K.L.W. and G.C.-R.; investigation, A.P.-C, K.L.W. and G.C.-R.; resources, J.A.C., A.P.-C, K.L.W. and G.C.-R.; data curation, A.P.-C. and K.L.W.; writing-original draft preparation, A.P.-C. and K.L.W.; writing-review and editing, J.A.C. and G.C.-R.; visualization, J.A.C.; supervision, J.A.C.; funding acquisition, A.P.-C. and J.A.C. All authors have read and agreed to the published version of the manuscript.

Funding: This research was funded by a joint grant from Bowel Disease Research Foundation, Ileostomy and Internal Pouch Association and Kingston Trust CIO.

Acknowledgments: This paper was submitted on behalf of the AFFINITY Trial Management Group, including Dean Harris, Gethin Williams, Parin Shah, and Jared Torkington. We would also like to thank the Research and Development teams at Cardiff and Vale, Cwm Taf Morgannwg, Swansea Bay and Aneurin Bevan University Health Boards.

Conflicts of Interest: The authors declare no conflict of interest. The funders had no role in the design of the study; in the collection, analyses, or interpretation of data; in the writing of the manuscript, or in the decision to publish the results.

\section{Appendix A. AFFINITY Questionnaire}

\section{Questions about your surgery and symptoms}

Which of these best describes your surgery?

Currently have ileostomy/stoma

Had ileostomy/stoma but now reversed $\square$

Never had ileostomy/stoma $\square$

\section{LARS Score}

Do you ever have occasions when you cannot control you flatus (wind)?

No, never $\square(0)$

Yes, less than once per week $\square$ (4)

Yes, at least once per week $\square$ (7)

Do you ever have any accidental leakage of liquid stool?

No, never $\square(0)$

Yes, less than once per week $\square$ (3)

Yes, at least once per week $\square$ (3)

How often do you open your bowels?

More than 7 times per day (24 h) $\square$ (4)

4-7 times per day (24 h) $\square$ (2)

1-3 times per day (24h) $\square(0)$

Less than once per day (24h) $\square$ (5) 
Do you ever have to open your bowels again within one hour of the last bowel opening?

No, never $\square(0)$

Yes, less than once per week $\square$ (9)

Yes, at least once per week $\square(11)$

Do you ever have such a strong urge to open your bowels that you have to rush to the toilet?

No, never $\square(0)$

Yes, less than once per week $\square$ (11)

Yes, at least once per week $\square(16)$

Have you had treatment for symptoms of low anterior resection syndrome/LARS?

Yes $\square \quad$ No $\square \quad$ Don't know $\square$

If your answers suggest you may benefit for treatment for low anterior resection syndrome/LARS, would you be happy for us to contact your GP/local colorectal team?

Yes $\square \quad$ No $\quad$

Faecal Microbiota Transplantation (FMT) is putting bacteria from someone else's faeces (poo) into the bowel. It is a recognized treatment for some bowel infections. It works by increasing the healthy bacteria in the bowel. Some people who have surgery for rectal cancer have altered bowel function after their ileostomy (stoma) is reversed. We think this may be caused by a lack of healthy bacteria in the bowel. This could be improved by FMT. The faeces from a healthy donor is mixed with saline (salt water) and would be inserted through the ileostomy before surgery to close it.

We want to know whether this sounds like an acceptable treatment to you.

For each statement please tick the box which fits most with your opinion.

\begin{tabular}{cccccc}
\hline & $\begin{array}{c}\text { Not } \\
\text { at All }\end{array}$ & A Little & Some-What & $\begin{array}{c}\text { Quite a } \\
\text { Bit }\end{array}$ & $\begin{array}{c}\text { Very } \\
\text { Much }\end{array}$ \\
\hline $\begin{array}{c}\text { FMT seems like an appropriate way to prevent } \\
\text { symptoms of LARS }\end{array}$ & & & & & \\
\hline FMT would fit my individual lifestyle & & & & & \\
\hline FMT seems like an effective way to prevent LARS & & & & \\
\hline I would be willing to try FMT & & & & \\
\hline
\end{tabular}

Which of these would be an acceptable FMT donor? (tick all that apply)

Partner/spouse $\square$

Blood relative $\square$

Friend $\square$

Anonymous healthy donor $\square$

None of above $\square$

Which of these routes for giving FMT is acceptable?

Via the ileostomy/stoma $\square$ 
Via the rectum (bottom)/enema $\square$

Via colonoscopy (magic eye/camera test) $\square$

None of above $\square$

Questions about you

What is your age?

What is your gender?

Male $\square$ Female $\square$ Other $\square$

How would you describe your ethnic origin?

Asian or Asian British $\square \quad$ Black or Black British $\square \quad$ Mixed $\square$

White British $\square$

Other ethnic group $\square$ Please write in

Are you ...?

Single $\square \quad$ Married/civil partnership $\square \quad$ Widowed $\square$

Co-habiting $\square \quad$ Separated/divorced $\square$

What is your level of education?

Degree or equivalent $\square \quad$ A Level or equivalent $\square$

GCSEs or equivalent $\square \quad$ Other qualification $\square$

No qualification $\square$

Which of these activities best describes what you are doing at present?

Employee in full time job $\quad$ Employee in part time job $\square$

Self-employed $\square \quad$ Full time education $\square$

Unemployed $\square \quad$ Permanently sick/disabled $\square$

Retired $\square \quad$ Looking after the home $\square$

Carer for spouse/relative $\square \quad$ Other $\square$

What is your current job or last job you did if not currently working?

Had you heard of FMT before receiving this questionnaire?

Yes- for clostridium difficile/infection $\square$

Yes- for ulcerative colitis/inflammatory bowel $\square$

No $\square$ 


\section{Appendix B. Focus Group Topic Guide}

Welcome and thank participants on arrival

Take consent

Introductions and purpose of the focus group

The idea of FMT

- $\quad$ The acceptability of FMT

- Their views prior to completing the questionnaire and since being given information

- Any elements that make FMT more or less acceptable

- What information they would want if they were to receive the treatment

Educational information

- The acceptability of the tone and style of the information

- Ease of understanding the content-is there too much jargon?

- Is the content adequate?

- What else would they want to know?

- Who should give it to the patient and how?

- What additional support would they like?

Participating in a trial

- The acceptability of the tone and style of the information

- Would they consider taking part in a trial of FMT?

- What would make them more or less likely to participate?

- What information would they want to help make the decision?

Any other comments you would like to make?

Thank participants

\section{References}

1. Bowel Cancer UK. Facts and Figures. Available online: http://www.bowelcanceruk.org.uk/informationresources/bowel-cancer-facts-figures/ (accessed on 24 November 2019).

2. Cornish, J.A.; Tilney, H.S.; Heriot, A.G.; Lavery, I.C.; Fazio, V.W.; Tekkis, P.P. A meta- analysis of quality of life for abdominoperineal excision of rectum versus anterior resection for rectal cancer. Ann. Surg. Oncol. 2007, 14, 2056-2068. [CrossRef] [PubMed]

3. Association of Coloproctology of Great Britain and Ireland. Guidelines for the Management of Colorectal Cancer. 2007. Available online: https:/www.acpgbi.org.uk/content/uploads/2007-CC-ManagementGuidelines.pdf (accessed on 24 November 2019).

4. Montedori, A.; Cirocchi, R.; Farinella, E. Covering ileo- or colostomy in anterior resection for rectal carcinoma. Cochrane Database Syst. Rev. 2010, 5, CD006878. [CrossRef] [PubMed]

5. Emmertsen, K.J.; Laurberg, S. Low anterior resection syndrome score: Development and validation of a symptom-based scoring system for bowel dysfunction after low anterior resection for rectal cancer. Ann. Surg. 2012, 255, 922-928. [CrossRef]

6. Bryant, C.L.; Lunniss, P.J.; Knowles, C.H.; Thaha, M.A.; Chanm, C.L. Anterior resection syndrome. Lancet Oncol. 2012, 13, e403-e408. [CrossRef]

7. Ziv, Y.; Zbar, A.; Bar-Shavit, Y.; Igov, I. Low anterior resection syndrome (LARS): Cause and effect and reconstructive considerations. Tech. Coloproctol. 2013, 17, 151-162. [CrossRef] [PubMed]

8. Ihn, M.H.; Kang, S.B.; Kim, D.W.; Oh, H.K.; Lee, S.Y.; Hong, S.M. Risk factors for bowel dysfunction after sphincter-preserving rectal cancer surgery: A prospective study using the Memorial Sloan Kettering Cancer Center bowel function instrument. Dis. Colon Rectum 2014, 57, 958-966. [CrossRef] [PubMed]

9. Siassi, M.; Hohenberger, W.; Lösel, F. Quality of life and patient's expectations after closure of a temporary stoma. Int. J. Colorectal Dis. 2008, 23, 1207-1212. [CrossRef] [PubMed]

10. Son, D.N.; Choi, D.J.; Woo, S.U.; Kim, J.; Keom, B.R.; Kim, C.H.; Baek, S.J.; Kim, S.H. Relationship between diversion colitis and quality of life in rectal cancer. World J. Gastroenterol. 2013, 19, 542-549. [CrossRef] [PubMed] 
11. Baek, S.; Kim, S.; Lee, C.; Roh, K.; Keum, B.; Kim, C.; Kim, J. Relationship between the severity of diversion colitis and the composition of colonic bacteria: A prospective study. Gut Liver 2014, 8, 17-76. [CrossRef] [PubMed]

12. National Institute for Health and Care Excellence Interventional Procedures Guidance [IPG485] Faecal Microbiota Transplant for Recurrent Clostridium Difficile Infection. 2014. Available online: https://www. nice.org.uk/guidance/ipg485 (accessed on 24 November 2019).

13. Paramsothy, S.; Kamm, M.A.; Kaakoush, N.O.; Walsh, A.J.; van den Bogaerde, J.; Samuel, D.; Leong, R.W.L.; Connor, S.; Ng, W.; Paramsoth, R.; et al. Multidonor intensive faecal microbiota transplantation for active ulcerative colitis: A randomised placebo-controlled trial. Lancet 2017, 389, 1218-1228. [CrossRef]

14. Pinn, D.M.; Aroniadis, O.C.; Brandt, L.J. Is fecal microbiota transplantation (FMT) an effective treatment for patients with functional gastrointestinal disorders (FGID)? Neurogastroenterol. Motil. 2015, 27, 19-29. [CrossRef] [PubMed]

15. Palmer, B.; Metcalfe, C.; Fraser, A.; Creed, T. Does education influence the acceptability of faecal microbiota transplantation in colitis: A cross-sectional study. Cogent. Med. 2016, 3, 1233685. [CrossRef]

16. Leung, F.H.; Savithiri, R. Spotlight on focus groups. Can. Fam. Phys. 2009, 55, 218-219. [PubMed]

17. Kreuger, R.A.; Casey, M.A. Focus Groups: A Practical Guide for Applied Research, 5th ed.; SAGE Publications: Thousand Oaks, CA, USA, 2014; pp. 63-81.

18. US Food and Drug Administration. Important Safety Alert Regarding Use of Fecal Microbiota for Transplantation and Risk of Serious Adverse Reactions Due to Transmission of Multi-Drug Resistant Organisms. 2019. Available online: https://www.fda.gov/vaccines-blood-biologics/safety-availabilitybiologics/important-safety-alert-regarding-use-fecal-microbiota-transplantation-and-risk-seriousadverse (accessed on 24 November 2019).

19. Mullish, B.H.; Nabil Quraishi, M.; Segal, J.P.; McCune, V.L.; Baxter, M.; Marsden, G.L.; Moore, D.J.; Colville, A.; Bhala, N.; Iqbal, T.H.; et al. The use of faecal microbiota transplant as treatment for recurrent or refactory Clostridium difficile infection and other potential indications: Joint British Society of Gastroenterology (BSG) and Healthcare Infection Society (HIS) guidelines. Gut 2018, 67, 1920-1941. [CrossRef] [PubMed]

20. Olesen, S.W.; Leier, M.M.; Alm, E.J.; Kahn, S.A. Searching for superstool: Maximizing the therapeutic potential of FMT. Nat. Rev. Gastroenterol. Hepatol. 2018, 15, 387-388. [CrossRef] [PubMed] 